\title{
Physiotherapy StUdents' Perceptions OF AN INNOVATIVE APPROACH TO Clinical Practice Orientation
}

\begin{abstract}
The transition from the classroom to clinical practice is stressful for many students. In the current situation in South Africa with the shortages of clinicians' posts in hospitals, this transition is even more difficult given the reduced time that clinicians have for supervising undergraduate students. The University of Stellenbosch initiated structured peer-led introduction to clinical education (SPLICE), during which senior physiotherapy students orientate second year students to clinical practice.

The aim of this study was to investigate the perceptions of all of the
\end{abstract} second, third and fourth year students who took part in these SPLICE sessions. This information was captured using a questionnaire with open and closed questions.

The response of all of the students was extremely positive. Common to all cohorts of students was the opinion of the motivational benefits of the sessions as well as the opinion that their confidence increased. Students in the various years of study differed in the ways in which they felt more confident. Closely linked were those comments referring to a sense of increased preparedness for clinical practice and a positive learning environment. A positive change in attitude towards clinical practice was also noted in many second year students.

Further research is needed into the effect that SPLICE might have had on the second year students when they enter clinical practice as third year students. The role and opinions of patients during these sessions, and indeed during any clinical education sessions, including clinical examinations, needs further investigation.

\section{KEY WORDS: CLINICAL EDUCATION, STUDENT MOTIVATION, CONFIDENCE, MENTORING.}

$\mathrm{G}$ overnment cutbacks on posts for hospital clinicians of all disciplines have resulted in enormous and far-reaching effects on undergraduate clinical education. Cutbacks have led to increased pressure on clinicians who now treat larger numbers of patients while still being expected to continue taking some responsibility for student supervision. Posts are increasingly being filled with new graduates, while senior clinicians are turning to private practice or overseas opportunities for a variety of reasons. New graduates therefore are forced to fulfil a complex and demanding role within days of graduating as junior clinicians.

The situation that develops is far from ideal. The inexperienced clinician lacks time, confidence and adequate support to effectively combine the roles of clinician, educator and role model. The third and fourth year physiotherapy students therefore have to take much more direct responsibility for the care of their patients, as well as for their own learning during clinical placements. Due to the lack of support for students, the provision of an effective introduction to clinical practice will present an ever-increasing challenge.

At the beginning of 2000 the Department of Physiotherapy at the University of Stellenbosch introduced an expanded Clinical Practice Module into the second year as part of the new undergraduate curriculum.

\section{AN OUTLINE OF THE CLINICAL PRACTICE MODULE}

The intention of the new module is to strongly support second year students in their introduction to clinical practice before they have to take responsibility for patient care in third year. Apart from visits to primary, secondary and tertiary health care institutions and small-group tutorials led by lecturers, the more innovative aspect is the structured peer- led introduction to clinical education (SPLICE) component. During this component the junior students 'shadow' and observe. Where appropriate they assist by the third and fourth year students. For logistical reasons the neurology, orthopaedic and medical and surgical care wards were selected at Tygerberg and Conradie Hospitals. The second year students were given the opportunity to conduct patient interviews and perform selected evaluation and treatment techniques under the supervision of senior students.

SPLICE took place for twelve hours over three weeks, i.e. six sessions of two

\section{CORRESPONDENCE TO:}

$M$ Faure

Department of Physiotherapy,

University of Stellenbosch

PO Box 19063

Tygerberg 7505

Tel: (021) 938-9300 
hours each. The second year students completed the following clinical tasks under the supervision of senior students:

- Client interviews

- Observation and assistance with the performance of selected evaluation techniques

- Observation and assistance with the performance of selected treatment techniques (including teaching home exercises)

The senior students were responsible for the following:

- Requesting the permission of their patients for the second year students' presence and participation in the session;

- Outlining the patient's condition to the second year student;

- Deciding together with the second year student, on the tasks which the junior student would perform; and

- Providing feedback to the second year after the session.

\section{AIM OF THE STUDY}

'Since students are the consumers of clinical education, it is important that they have the opportunity to express their needs' (Walker and Openshaw 1994).

The main aim of this descriptive study was to examine the perception of students of the SPLICE sessions. The following were therefore investigated:

- The perceptions of the junior and senior students of the value of this rotation;

- The attitudes/perceptions of the second year students towards clinical practice before and after the rotation; and

- The observed reaction of the patients to the presence and participation of the second year students in their treatment sessions.

\section{METHODOLOGY}

Data were collected via self-administered questionnaires. These were completed by all of the second year physiotherapy students, as well as by those third and fourth year students who were accompanied by junior students during the SPLICE attachment.

The questionnaires were completed anonymously during class-time at the

Table 1: Responses describing the value attached to the experience

\begin{tabular}{|c|c|c|}
\hline RESPO N SE & COMMENTS: 2nd year & COMMENTS: 3rd \& 4th year \\
\hline Positive & $\begin{array}{l}\text { - More self confidence } \\
\text { - Less pressure to perform / } \\
\text { stress free atmosphere } \\
\text { - Good preparation for next year } \\
\text { - Senior student present to help } \\
\text { and confirm } \\
\text { - Confirmation that I knew my work } \\
\text { - Learnt }\end{array}$ & $\begin{array}{l}\text { - Keeps you on your toes } \\
\text { - Forces you to do more } \\
\text { preparation } \\
\text { - Gives you confidence while } \\
\text { someone is watching } \\
\text { - O pportunity to test yourself } \\
\text { - Learnt }\end{array}$ \\
\hline N egative & & $\begin{array}{l}\text { - Takes too much time } \\
\text { - Patients did not interact well } \\
\text { - Difficult as it was our first } \\
\text { clinical block }\end{array}$ \\
\hline 0 ther & $\begin{array}{l}\text { - Gives a taste of what's to come } \\
\text { - Practical experience of } \\
\text { physiotherapy } \\
\text { - No comment }\end{array}$ & $\begin{array}{l}\text { - Have to share your knowledge } \\
\text { - Checks your theory } \\
\text { - No comment }\end{array}$ \\
\hline
\end{tabular}

Figure 1: The percentage of the 2 nd, 3rd and 4th year students' responses to the sessions

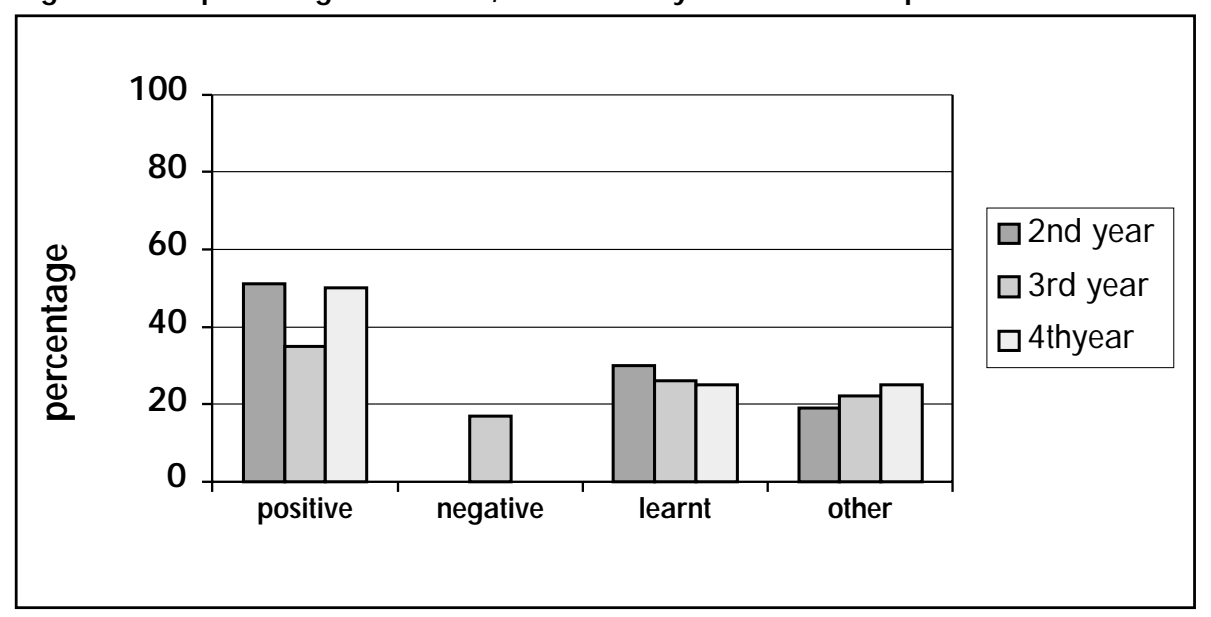

end of October 2000. This ensured a high response rate.

\section{Instrumentation}

Two similar and comparable questionnaires were devised, with the one to be completed by second year and the other by third and fourth year students. Both consisted of Section A relating to logistics and the extent of the practical experience provided during the SPLICE programme, and Section $\mathrm{B}$ relating to the students' experiences and perceptions of, and attitudes towards, the programme.

Questions were answered by a combination of:

a) Ticking yes/no or numerical boxes;

b) Specifying pathology, evaluation and treatment techniques observed or performed; c) Ticking alternatives relating to opinions, attitudes or perceptions of SPLICE; and

d) Qualitative and descriptive comments relating to rotations.

\section{Data analysis}

Responses to a), b) and c) were coded and their frequencies were calculated. Responses to d) were grouped independently by each of the three researchers in accordance with qualitative methodology. When necessary, information was re-classified until consensus was reached. Where appropriate, the data were analysed using two-sample comparisons between the responses to similar questions included in the questionnaires of the second year students and the third and fourth year students on an itemby-item basis. 
Table 2: Reponses describing the value of the experience for junior students as perceived by the senior students.

\begin{tabular}{|l|l|}
\hline RESPON SE & \multicolumn{1}{c|}{$\begin{array}{c}\text { COMMENTS OF SEN IOR STUDEN TS' PERCEPTION } \\
\text { REGARDIN G THE JUN IOR STUDEN TS' EXPERIEN CE }\end{array}$} \\
\hline Positive & $\begin{array}{l}\text { - They gained more confidence with patients } \\
\text { - More at ease in clinical } \\
\text { - Good introduction to clinical } \\
\text { - G radually exposed to clinical/ not thrown in at the deep-end } \\
\text { - Enjoyed contact with patients } \\
\text { - Real experience, not just practice on classmates } \\
\end{array}$ \\
& - They were able to draw on our experiences in clinical \\
\hline O ther & $\begin{array}{l}\text { - Learnt } \\
\text { - Exercise with theory background } \\
\text { - No comment }\end{array}$ \\
\hline
\end{tabular}

Figure 2. Students' enjoyment of the sessions

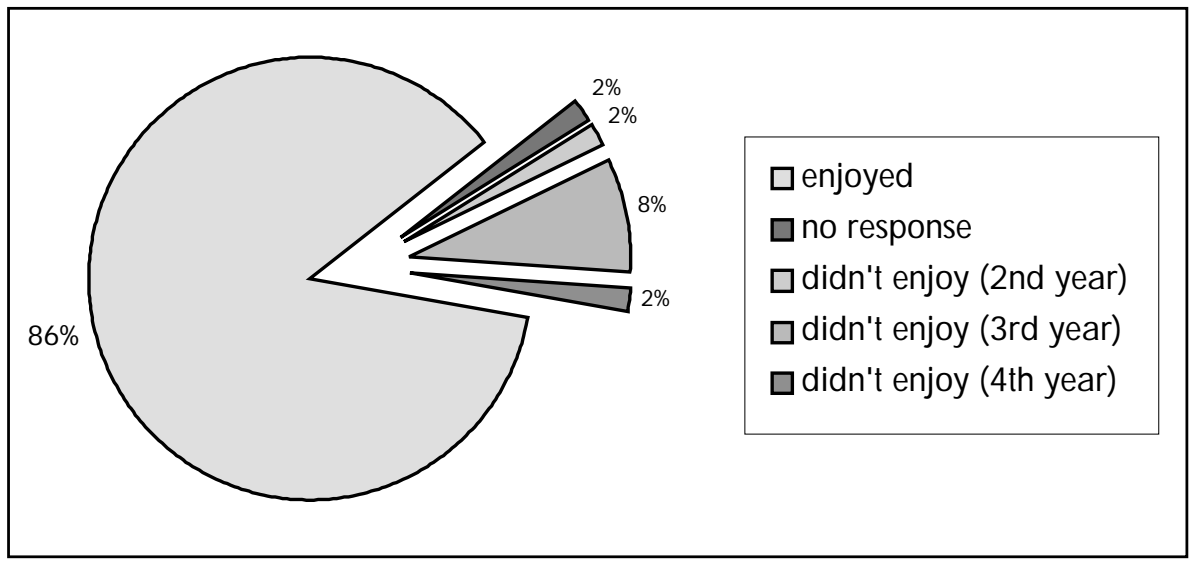

Table 3: Comparison of frequency of themes for the 'reasons to continue the sessions', given by the students

\begin{tabular}{|l|c|c|c|}
\hline \multicolumn{1}{|c|}{ COMMEN T } & \multicolumn{3}{c|}{ REASON TO CONTIN UE } \\
\hline Year of study & 2 nd & 3 rd & 4 th \\
\hline Integrating theory into practice & 3 & 0 & 0 \\
\hline Motivating/ enriching/ stimulating & 13 & 2 & 2 \\
\hline Personal interaction with patients & 3 & 0 & 0 \\
\hline Feel more prepared for clinical & 14 & 1 & 1 \\
\hline Increased confidence & 3 & 0 & 0 \\
\hline + learning environment & 6 & 3 & 1 \\
\hline N egative comments & 0 & 0 & 0 \\
\hline
\end{tabular}

\section{RESULTS}

In total 60 questionnaires were returned:

- second year students: $100 \%$ response rate $(n=34)$

- third year students: $85 \%$ response rate $(\mathrm{n}=17)$

- fourth year students: $90 \%$ response rate $(n=9)$

Many responses to the questions referred to educational aspects of knowledge and skill acquisition. However, the responses are summarised in Table 1 . Affirmative comments that referred to student learning could have been included as a positive response. However, as many students referred to 'how much they had learnt', it was decided to include "learnt" as a separate, although positive response.

Figure 1 depicts the percentages of these responses of each of the student cohorts.

Do you think it was a valuable experience for the second year students?

Please motivate why.

This question was only included in the questionnaire for the senior students.

No negative comments were given (Table 2). Furthermore, the positive comments made by these students concur with those of the second year students (Table 1).

\section{Did you enjoy the shadow ing sessions? - \\ Why?}

Figure 2 represents the responses to this question. The second year students gave a variety of reasons for enjoying the sessions, such as '...gave exposure ... I now know what to expect', and 'it was a good experience' and '...could see the effects of treatment'. Many others referred to what they felt they had learnt. The second year student who did not enjoy the sessions commented '... it was the relationship with the (senior) student - it was just something you have to do, no "let's go and do it!" attitude'.

A typical comment of senior students was 'I would have liked to have done it myself'. A third year student who did not enjoy the sessions volunteered that 'it was the beginning of the block and I needed to find my feet first'. This student made a similar comment concerning the value of the sessions (cf. Table 1).

\section{Do you think that these sessions should} continue? Why?

The students unanimously indicated that the SPLICE sessions should continue and the comparison of their comments is contained in Table 3.

All comments of the 'value', enjoyment' and 'reasons to continue' were re-grouped into categories for comparison. The frequency of these categories 
occurring in the responses of the second year students is portrayed in Figure 3.

Express in ONE word the way you felt before you started the shadowing block and In ONE word explain how you NOW feel about clinical physiotherapy for next year.

The questionnaire opened with the first statement and ended with the second.

The words used to describe these attitudes were grouped into positive and negative categories (Table 4). The change in attitude of the second year students towards clinical work, before and after, the SPLICE sessions, is indicated in Figure 4.

How do you think that patients experienced second year student shadowing you? Positively / Negatively. Briefly explain why. All students were asked this question. Only one student - who was in third year - indicated the 'negatively' option. However, $37 \%(n=7)$ misunderstood the question, and answered positively, but inappropriately. These students appeared to have interpreted the question as 'Do you think that the (second year) student experienced the patient positively or negatively'. The reasons that were given as to why the patient responded positively to the junior students presence, included that 'They [the patient] enjoyed the extra attention', '... liked another opinion...' and commonly '...liked to feel that she/he was helping...'.

\section{DISCUSSION}

It is quite evident that not only were the SPLICE sessions perceived very positively by second year students, but also by senior students and by patients. Interestingly, senior students expressed the benefit mainly in educational terms. However, only those comments relating to general attitudes and perceptions will be discussed below.

Carlisle (2000) states that a strong base of evidence exists to support the idea that self-confidence in learning and of how well a task can be tackled fundamentally affects students' approach and understanding. The opinion of all students was that the SPLICE sessions had indeed contributed to their sense of increased self-confidence. Furthermore,

Figure 3. Comparison of frequency of categories for the reasons for the 'enjoyment', 'value' and 'continuation of the sessions' given by 2 nd year students. (pts = patients)

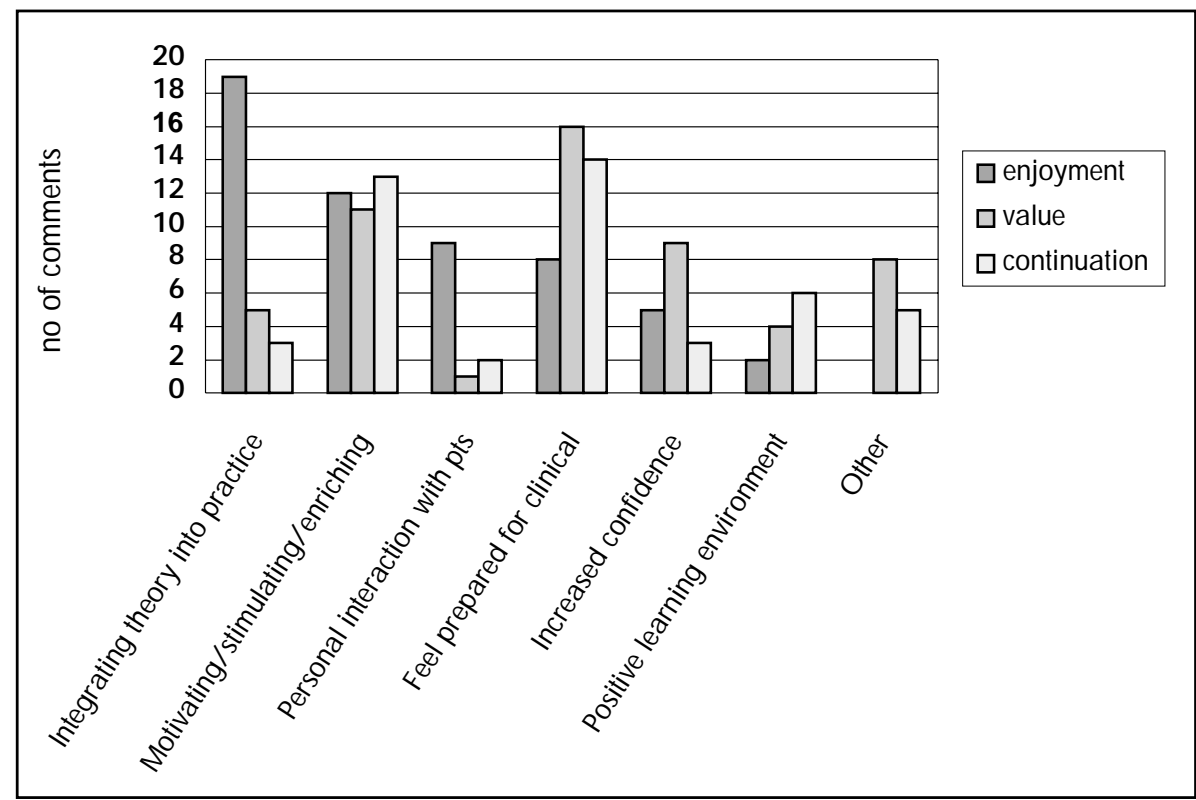

Figure 4: Change in attitude of 2 nd year students towards clinical work before and after the sessions.

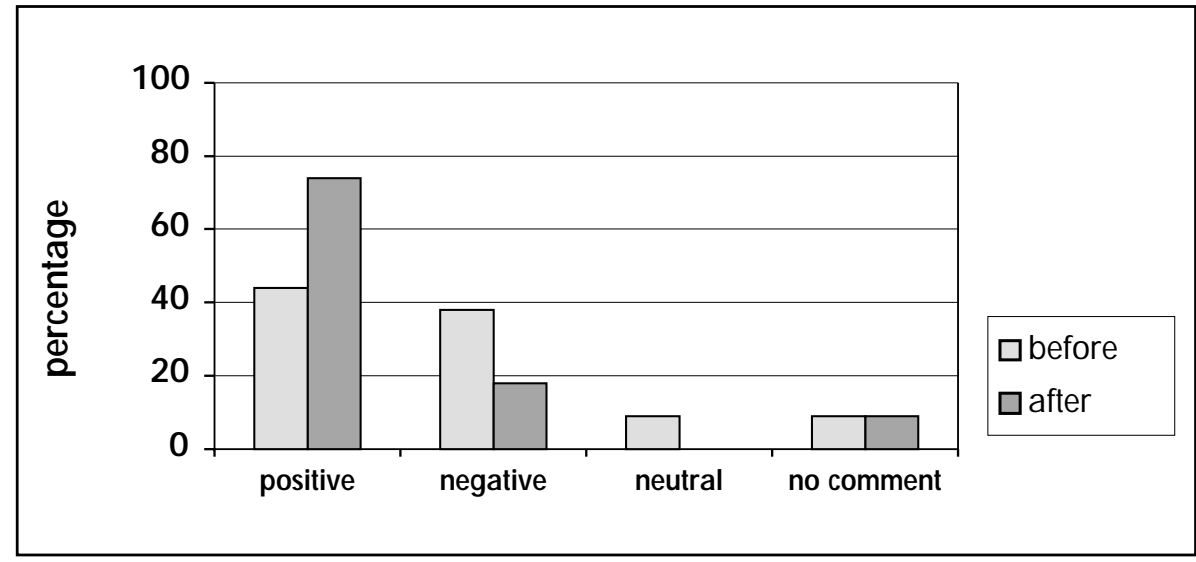

the overwhelming opinion of all students was that the sessions should be continued.

\section{FEEDBACK FROM SECOND YEAR STUDENTS}

Students typically described the sessions as stimulating and enriching.

\section{Themes - 'value' and 'enjoyment'}

It is interesting to note that many students attached value to feeling more prepared for clinical practice and having increased confidence, whereas less students expressed themselves this way for their enjoyment of the sessions. On the other hand, more students commented that they enjoyed interacting with patients than those who responded in this way to the questions on the value of the SPLICE sessions (figure 3).
Table 4: Words used to describe positive and negative attitudes

\begin{tabular}{|l|l|}
\hline \multicolumn{1}{|c|}{ POSITIVE } & \multicolumn{1}{c|}{ NEGATIVE } \\
\hline Excited & N ervous \\
\hline Enthusiastic & Unsure \\
\hline Challenged & Confused \\
\hline Great & Scared \\
\hline Prepared & $\begin{array}{l}\text { W eary and } \\
\text { Anxious }\end{array}$ \\
\hline Positive & \begin{tabular}{l} 
Terrified \\
\hline Better
\end{tabular} \\
\hline Learnt & \\
\hline A mped & \\
\hline Intrigued & \\
\hline Anticipation & \\
\hline
\end{tabular}


According to the Oxford Dictionary, 'to value' means to '...be of worth, attach importance to, appreciate ...' whereas 'enjoyment' is '...to experience pleasure, take delight in ...' The word 'value' therefore might be considered by students to have more legitimacy than 'enjoyment' during a learning opportunity.

The words motivated, enriched and stimulated are adverbs that one would expect students to use when referring to a positive learning environment. These words were amongst the most common used by students when responding to questions relating to value and enjoyment. Many reasons could contribute to the sessions being experienced as a positive learning environment. These include the supported and gradual way that junior students were introduced to clinical practice, as well as the mentoring role that senior students assumed.

Galicia et al (1997) suggests that a mentor provide support and encouragement to a novice who is striving to attain success within a chosen professional area. They also maintain that although definitional diversity characterises the literature on mentorship, there is strong agreement that mentorship is a helpful relationship usually focussed on achievement. It can include any or all of the following components: emotional support, direct assistance with career or professional development and role modelling. Mentoring is also linked to academic success and although there is disagreement about the duration of the mentoring relationship, it can last for as long as ten years or be as brief as a single encounter. The senior students who appear to have taken on a mentoring role, also maintained their responsibility for patient care, thereby relieving the junior students of the stress that many might have felt during their first experience of clinical practice.

Bligh (1999) suggests that among other criteria, the mentoring process should be positive, facilitative and not be part of assessment or performance monitoring procedures. The SPLICE sessions are one of very few occasions when junior students are able to ask questions of a more senior person, who has no role in formally assessing their performance. This too, might have assisted in creating a non-threatening environment. Therefore the relatively stress free clinical introduction might also have contributed to the students perception of a positive learning environment.

\section{Theme - attitudes}

The majority of students were very positive throughout, with comments such as 'I can't wait to start now', 'I look forward to clinical because it's the real thing', '... loved my shadowing... ', and 'look forward to working with patients'. The majority of students also included comments that related to the application of knowledge and skills, but a discussion of these is beyond the scope of this paper. Suffice is it to note that these comments reinforce the standpoint that these sessions motivated students to looking forward to using the knowledge and skills that they gained in the classroom.

A significant number of students appeared to fear that they would fail at clinical practice. Cupit (1988) refers to Message (1986) and Fisher (1984) who state that stress can be 'anticipatory' rather than 'responsive'. These authors maintain that much energy might be spent not only on thinking about a future event, but also about the consequences of performances. These authors also claim that the stress might be so great as to seriously hinder an adequate performance. Malik (2000) states this even more strongly: 'Much of this psychological morbidity appears to be caused by course-related stress, which some workers have described as student abuse.' Given the current situation in physiotherapy education as well as the inherent uncertainty of clinical practice, clinicians and undergraduate students in South Africa face a situation that is potentially enormously stressful. This not only has ethical implications for patient care but also for effective training and work satisfaction.

Typical comments made by students who used words indicating a negative attitude to clinical practice included: 'Sure I can handle it, but am scared of patients if I don't know how to treat them ... more a question of uncertainty or something new that must be done'; 'Although I know what lies ahead, it still makes me scared - however I am excited...' The 'weary and anxious' student commented 'I wonder if I know enough to do clinical PT next year - you are working with real people with real problems.'

However, all the above students responded that they had experienced the sessions as 'enjoyable', having 'value' and agreed that they should be continued, with one of them adding 'but feeling much better now due to shadowing'.

These comments suggest that the transition from pre-clinical to clinical education is indeed stressful for some students. Although it might be argued that some stress is unavoidable, it would be wise to make an effort to investigate the ways in which unhealthy stress can be minimized (Cupit 1988).

Those students who used more positive terms following the sessions elaborated with comments such as 'Now I have an idea of what to expect', 'I know more or less what to do for next year', and 'I am already less scared...' All these comments would suggest that the sessions had in some way motivated them to anticipate clinical practice more positively.

\section{FEEDBACK FROM THIRD AND FOURTH YEAR STUDENTS \\ Themes - value and enjoyment}

The senior students appear to have enjoyed introducing juniors to clinical practice. As was the case with junior students, many senior students commented that they valued or enjoyed various motivational benefits as well as an increased confidence. Comments such as 'it is an opportunity to test yourself', 'keeps you on your toes' and 'gives you confidence while someone is watching you' were rather unexpected, as it is the experience of clinicians and lecturers that students generally find it threatening to be observed. Galicia et al (1997) state that mentorships tend to be reciprocal and personal relationships in which mentors show greater experience relative to their protégés within a particular environment. Therefore, an explanation for the senior students' positive attitude towards the SPLICE sessions could be that as their clinical experience was greater than that of the 'protégés', 
the latter feel more confident. Being able to answer questions of junior students also was noted as increasing confidence.

The single most important factor in the perceived success of a support scheme is the establishment of a good relationship (Malik 2000). Kilminster and Jolly (2000) agree that 'The quality of supervision relationship is probably the single most important factor for the effectiveness of supervision, more important than the supervisory methods used.' As senior students introduction to clinical practice was still comparatively recent, there appears to have been a real desire on their part to play a role in assisting junior students to feel more at ease in the hospital environment.

Interpersonal skill takes precedence over professional/technical skill in students' perceptions (Cross 1995), and the comments received by junior students reinforce this belief. Stewart et al (2000) explored the beliefs of house officers about their competence, and concluded that 'they made assessments about their competence from the lack of negative comments made by others'. It appears that neither group of students made negative comments to each other. This might also have been a reason for students perception of feeling more confident in their abilities.

Only one junior commented '...a poor relationship with the student [senior] - it was just something you have to do - no lets go and do it attitude'. Only two students, both in third year, appear to have found the sessions stressful. On both occasions the stress appeared to be as a result of the sessions coinciding with placement changeovers, 'it takes too much time' and '... difficult as it was our first clinical block'.

\section{Theme - attitudes}

Although the attitude of senior students was not specifically evaluated, this can be indirectly noted as being very positive as $100 \%$ of them stated that the SPLICE should be continued.

\section{Perceptions of patients' response}

The last question on the questionnaire for senior students was whether they considered that patients responded positively or negatively to junior students.
Reasons why this question might have been misunderstood could be that students were getting tired of reading and answering questions, or that they presumed that all the questions focussed on their own experiences.

There are many ethical issues related to clinical education. These include the patient's right of privacy and consent to being part of an educational exercise, as well as the power relationships that even junior student might be perceived to have in the clinical environment. Thus, the role and attitude of patients is fundamental to the learning environment and therefore also, indirectly, to the response of students to clinical practice.

Lynoe et al (1998) state that the preparedness of patients to participate in training is an important precondition for good education. The students' feedback suggests that apart from the positive attribute of the behaviour of junior student, patients enjoyed the extra attention that they received and enjoyed feeling that they were contributing to the 'teaching' session.

\section{FEEDBACK FROM SECOND, THIRD AND FOURTH YEAR STUDENTS - Continuation of the SPLICE sessions}

While students of all three years unanimously indicated that the sessions should be continued, it is interesting to note that the seniors provided fewer comments motivating for the continuation of SPLICE than did the juniors. A reason might be that senior students considered that they had already indicated why they thought the sessions were beneficial for junior students and that this further motivation was therefore unnecessary. Furthermore, the fourth year students would not take part in these sessions again. However, there was agreement between all three years on the motivational/enriching/stimulating aspects of SPLICE, the positive learning environment and a sense of increased confidence and of being more prepared for clinical practice.

\section{RECOMMENDATIONS}

It is apparent that the SPLICE sessions had important benefits, not only for junior students, but also for seniors. Taken together with the perceptions of the educational benefits, it would appear that there is certainly room for the continuation and development of a SPLICE model. However, certain factors need to be addressed. These include:

- The timing of the sessions to accommodate senior students

- The preparation given to both junior and senior students prior to the sessions

- Identifying appropriate and more objective markers to gather an evidence-base for the SPLICE model for clinical introduction

- Research into the role and opinions of patients in clinical education

\section{REFERENCES}

Bligh J 1999 Mentoring: an invisible support network. Medical Education 33: 002-003

Carlisle C 2000 Reflecting on levels of confidence and competence in skills acquisition. Medical Education 34: 886-887

Cross V 1995 Perception of the Ideal Clinical Educator in Physiotherapy Education. Physiotherapy 81(9): $506-513$

Cupit RL 1988 Student Stress: An Approach to Coping at the Interface Between Preclinical and Clinical Education. The Australian Journal of Physiotherapy. 34(4): 215-219

Galicia AR, Klima RR, Date ES 1997 Mentorship in Physical Medicine and Rehabilitation Residencies. American Journal of Physical Medicine Rehabilitation 76(4): 268 - 275

Kilminster SM and Jolly BC 2000 Effective supervision in clinical practice settings: a literature review. Medical Education 34: 827-840

Lynoe N, Sandlund M, Westberg K, Duchek M 1998 Informed consent in clinical training patient experiences and motives for participating. Medical Education 32: 465-471

Malik S 2000 Students, tutors and relationships: the ingredients of a successful support scheme. Medical Education 34(6): 635-641

Stewart J, O'Halloran C, Barton JR, Singleton SJ, Harrigan $\mathrm{P}$ and Spencer $\mathrm{J} 2000$ Clarifying the concepts of confidence and competence to produce appropriate selfevaluation measurement scales. Medical Education 34: 903-909

Triggs Nemshick M, Shepard KF 1996 Physical Therapy Clinical Education in a 2:1 Student-Instructor Education Model. Physical Therapy 76(9): 968-984

Walker EM, Openshaw S 1994 Educational Needs as Perceived by Clinical Supervisors. Physiotherapy 80(7):424-431 